\title{
O modus operandi no conselho municipal de alimentação escolar em um município do Noroeste do Rio Grande do Sul (Brasil): reflexões sobre a sua institucionalização
} Modus operandi in the municipal council of school food in a Northwest municipal of Rio Grande do Sul (Brazil): reflections on its institutionalization

\section{David Basso Indaia Dias Lopes}

Universidade Regional do Noroeste do Estado do Rio Grande do Sul - Unijuí - ljuí - Rio Grande do Sul - Brasil

\section{Dedilhana Lamare Manjabosco Hübner}

Universidade Regional do Noroeste do Estado do Rio Grande do Sul - Unijuí - ljuí - Rio Grande do Sul - Brasil

\section{Denize Grzybovski}

Universidade Regional do Noroeste do Estado do Rio Grande do Sul - Unijuí - ljuí - Rio Grande do Sul - Brasil Indaia Dias Lopes

Universidade Regional do Noroeste do Estado do Rio Grande do Sul - Unijuí - ljuí - Rio Grande do Sul - Brasil

\section{Roseli Fistarol Krüger}

Universidade Regional do Noroeste do Estado do Rio Grande do Sul - Unijuí - ljuí - Rio Grande do Sul - Brasil

\begin{abstract}
Resumo: Este artigo tem como objetivo compreender a institucionalização e o funcionamento do Conselho de Alimentação Escolar (CAE) enquanto um conselho gestor de política pública no município de ljuí, localizado no Noroeste do Estado do Rio Grande do Sul (RS), bem como analisar sua atuação e os desafios da gestão. O referencial teórico utilizado foi de conselhos gestores de políticas públicas na perspectiva da gestão social. Trata-se de uma pesquisa exploratória, cuja estratégia de investigação foi o estudo de caso único, com abordagem qualitativa dos dados coletados por meio de pesquisa documental e entrevistas. Os resultados apontam a atuação do CAE em ljuí/RS como efetiva, apesar dos entraves enfrentados. O principal desafio identificado foi quanto à recomposição de seus membros, processo que está ocorrendo com êxito. Conclui-se que a institucionalização de um CAE ocorre a partir da interação entre os diferentes órgãos que compõem um programa governamental, como no caso do PNAE, e que o seu funcionamento depende da atuação efetiva de todos os atores envolvidos.

Palavras-chave: Gestão social. Alimentação escolar. Conselho de Alimentação Escolar.
\end{abstract}

\begin{abstract}
This article aims to understand the institutionalization and functioning of the School Feeding Council (CAE) as a public policy management council in the municipality of ljuí, located in the Northwest of the State of Rio Grande do Sul (RS), as well as to analyze its performance and management challenges. The theoretical reference used was from public policy management councils in the perspective of social management. It is an exploratory research whose research strategy was the single case study, with qualitative approach of the data collected through documentary research and interviews. The results point out the CAE's performance in ljuí/RS as effective, despite the obstacles faced. The main challenge identified was the recomposition of its members, a process that is occurring successfully. It is concluded that the institutionalization of a CAE occurs from the interaction between the different organs that make up a governmental program, as in the case of the PNAE, and that its functioning depends on the effective action of all the actors involved.
\end{abstract}

Keywords: Social management. School feeding. School Feeding Council. 


\section{Introdução}

No Brasil, um Conselho de Alimentação Escolar (CAE) é parte integrante dos Conselhos Gestores de Programas Governamentais e estes estão ligados à execução de ações governamentais específicas e focalizadas (ALLEBRANDT, 2016). Os conselhos gestores são locus potencial para a prática da gestão social (TENÓRIO, 2016a), pois nesses locais as pessoas podem apresentar suas inquietações ao gestor público e participar das deliberações. $O$ envolvimento tanto dos conselheiros quanto da população de forma geral nas discussões e deliberações faz com que os conselhos sejam praticantes da gestão social (KRONEMBERGER; MEDEIROS; DIAS, 2016).

O CAE é um órgão deliberativo, fiscalizador e de assessoramento do Programa Nacional de Alimentação Escolar (PNAE), composto de no mínimo sete membros titulares mais suplentes (FNDE, 2016). É formado por membros da sociedade com representantes do Poder Executivo, dos pais de alunos, de professores e segmentos da sociedade civil. Sua criação ocorreu a partir da descentralização do PNAE, a qual teve início em 1994. Sua função é realizar o controle social do PNAE, abarcando o interesse da sociedade, da coletividade e da cidadania, e, por essa razão, esses conselhos são considerados uma conquista da sociedade civil (FROEHLICH, 2010).

Levando em consideração a importância do CAE para que o PNAE tenha efetividade, questionase de que forma os CAEs são institucionalizados nos municípios brasileiros. Para tanto e com a pretensão de obter profundidade analítica, desenvolveu-se um estudo do processo de institucionalização do CAE em ljuí, um município de médio porte no interior do Rio Grande do Sul (Brasil). Com os resultados, espera-se objetivamente identificar as atividades que esse órgão desempenha no contexto local e descrever os principais desafios enfrentados pelos gestores do CAE/ljuí no cotidiano.

ljuí é um dos 5.570 municípios brasileiros que constituíram CAEs nos 26 estados da Federação e no
Distrito Federal (DF), envolvendo aproximadamente 80 mil conselheiros (FNDE, 2016). Os membros de um CAE são selecionados em cada segmento da sociedade e o exercício do mandato é equiparado à prestação de serviço público de relevância social (FROEHLICH, 2010). Os agricultores familiares representam um desses segmentos da sociedade civil organizada e também podem fazer parte do CAE, cujo espaço representa uma oportunidade de participar ativamente na qualidade de produtores de gêneros alimentícios fornecedores ao PNAE, bem como de informar aos conselheiros a respeito das especificidades da produção local (MOSIMANN, 2014), como culturas, ciclo de produção sazonalidade, variáveis que afetam a disponibilidade produtos rurais ao PNAE.

Tal problemática é relevante para o estudo, tendo em vista que nem todos os CAEs são efetivos nas suas ações. Triches (2010) constatou que a instalação do CAE no município de Rolante (RS) foi resultado de um processo de discussão junto à comunidade, principalmente no sentido de fazê-la compreender o papel desse conselho e de inseri-la nesse movimento. A autora relata que nesse município ocorreu o efetivo envolvimento da comunidade na gestão do programa, seja por meio da frequência das reuniões, participação dos conselheiros nas discussões sobre o que comprar de gêneros alimentícios, indo além do papel fiscalizador do CAE. Entre outras conquistas do CAE/Rolante, Triches (2010) destaca a defesa dos consumidores. Esse conselho conseguiu garantir e manter a qualidade dos alimentos oferecidos nas escolas, bem como sua disponibilidade e regularidade, sendo essa uma preocupação observada nas atas do conselho desde o início da descentralização do PNAE. Foram efetuadas visitas regulares de fiscalização nas escolas, o que fez diminuir as reclamações e aumentar a satisfação dos próprios alunos.

Nos municípios de Santa Rosa de Lima, Rio Fortuna e Lauro Muller, no estado de Santa Catarina, Mosimann (2014) constatou resultados diferentes. As reuniões eram esporádicas (apenas duas vezes por ano) e, no município de Lauro Muller, as primeiras 
reuniões foram realizadas apenas para prestação de contas. A partir de 2013, passaram a ser realizadas trimestralmente. A referida autora constatou que, no processo de constituição do CAE, não houve preparação dos conselheiros para assumir o cargo. As capacitações oferecidas pelo centro colaborador em alimentação e nutrição do escolar (CECANE) ocorreram somente em 2013, ficando evidente que não existia clareza nas informações dos membros desse órgão, ocorrendo troca de informações de forma isolada e bastante informal. Para que o controle social tenha efetividade, a troca de informações e a capacitação são fundamentais no conselho (MOSIMANN, 2014).

Este artigo está estruturado em cinco seções, sendo a primeira representada por esta introdução. $A$ seção dois apresenta o referencial teórico que dá suporte à análise, seguida da terceira seção, onde consta a metodologia utilizada. Na seção quatro, são discutidos os principais resultados, e, por fim, a última seção expõe as conclusões.

\section{Conselhos gestores de Políticas Públicas}

No contexto brasileiro, a Constituição Federal de 1988 (CF/88) representou uma vitória da população em conflito com o Estado na busca de seus direitos sociais básicos. A CF/88 reconhece por meio das leis orgânicas os conselhos gestores, os quais podem compor as três instâncias de poder a saber: federal, estadual ou municipal (LAVINAS; MAGNO, 2016). Os conselhos são considerados órgãos colegiados, instituídos de forma permanente e com função deliberativa (KRONEMBERGER; MEDEIROS; DIAS, 2016), conceituação que equipara os referidos conselheiros a um grupo de pessoas que se reúnem para tratar de um objetivo comum, que não podem ser extintos por nenhuma lei estadual ou municipal e com poder de decisão.

Os conselhos são compostos pela pluralidade de atores que, embora tenham interesses distintos, têm como objetivo representar determinada demanda social (VILLELA; MEDEIROS, 2016). Quase a totalidade dos municípios brasileiros possui conselhos instituídos em diferentes áreas, com prevalência em: saúde, assistência social, educação e direitos da criança e do adolescente (KRONEMBERGER; MEDEIROS; DIAS, 2016).

Para que um conselho seja criado deve haver envolvimento da população do município, o que implica na elaboração e aprovação de uma lei municipal por parte da Câmara de Vereadores, a qual deverá abarcar objetivos, composição, competências e atribuições a ser desempenhadas pelos conselhos criados (KRONEMBERGER; MEDEIROS; DIAS, 2016), tendo em vista que suas funções são específicas, como consta no Quadro 1. Alguns conselhos possuem funções apenas consultivas enquanto outros possuem funções consultivas e deliberativas.

\section{Quadro 1: Tipos de conselhos e funções exercidas.}

\begin{tabular}{|c|c|c|}
\hline Tipo & Conselho & Funções \\
\hline $\begin{array}{l}\text { Programas } \\
\text { Governamentais }\end{array}$ & $\begin{array}{l}\text { Conselho } \\
\text { Municipal de } \\
\text { Alimentação } \\
\text { Escolar }\end{array}$ & $\begin{array}{l}\text { Fiscalizar os } \\
\text { recursos federais } \\
\text { repassados pelo } \\
\text { FNDE para a } \\
\text { alimentação } \\
\text { escolar e garantir } \\
\text { boas práticas } \\
\text { sanitárias e de } \\
\text { higiene dos } \\
\text { alimentos. }\end{array}$ \\
\hline Temáticos & $\begin{array}{l}\text { Conselho } \\
\text { Municipal de } \\
\text { Defesa dos } \\
\text { Direitos da } \\
\text { Pessoa Idosa }\end{array}$ & $\begin{array}{l}\text { Deliberar e } \\
\text { fiscalizar as ações } \\
\text { e serviços de } \\
\text { natureza pública e } \\
\text { privada que visam } \\
\text { assegurar os } \\
\text { direitos sociais da } \\
\text { pessoa idosa. }\end{array}$ \\
\hline Territoriais & $\begin{array}{l}\text { Conselho } \\
\text { Distrital de } \\
\text { Saúde }\end{array}$ & $\begin{array}{l}\text { Auxiliar a } \\
\text { administração } \\
\text { pública e o } \\
\text { conselho municipal } \\
\text { de saúde na } \\
\text { análise, no } \\
\text { planejamento, na } \\
\text { formulação e na } \\
\text { fiscalização da } \\
\text { política de saúde. }\end{array}$ \\
\hline Globais & $\begin{array}{l}\text { Conselho } \\
\text { Municipal de } \\
\text { Desenvolvimento } \\
\text { Rural } \\
\text { Sustentável }\end{array}$ & $\begin{array}{l}\text { Consultiva, } \\
\text { deliberativa e } \\
\text { fiscalizadora da } \\
\text { política de } \\
\text { desenvolvimento } \\
\text { rural sustentável } \\
\text { no município. }\end{array}$ \\
\hline
\end{tabular}

O CAE é um conselho gestor de uma política pública, o PNAE, e visa estabelecer o controle social do programa de alimentação escolar. O controle 
social se dá de forma individual ou coletiva pelos membros da sociedade, através de entidades organizadas juridicamente ou não. Esse ato realiza-se por meio dos diversos instrumentos jurídicos disponíveis ao cidadão para que possa "fiscalizar, vigiar, velar, examinar, inquirir e colher informações a respeito de algo" (SIRAQUE, 2009 apud TENÓRIO, 2016, p. 23).

Para Lavinas e Magno (2016, p. 146), uma das principais contribuições dos conselhos gestores foi de "garantir a descentralização do poder público e permitir a maior participação cidadã dentro dos trâmites burocráticos do Estado". Após a promulgação da CF/88 o Brasil avançou em termos de uma gestão governamental mais democrática possibilitando a participação da sociedade civil na formulação, execução e no desenvolvimento das políticas públicas (LAVINAS; MAGNO, 2016).

Os conselhos são compostos tanto por membros do poder público quanto da sociedade civil e deve possuir uma composição paritária, ou seja, para cada conselheiro representante do Estado deve haver um representante da sociedade civil (KRONEMBERGER; MEDEIROS; DIAS, 2016). No caso do CAE, o mesmo é formado por sete membros titulares, mais sete suplentes, conforme pode-se visualizar na Figura 1.

Figura 1: Composição do CAE.

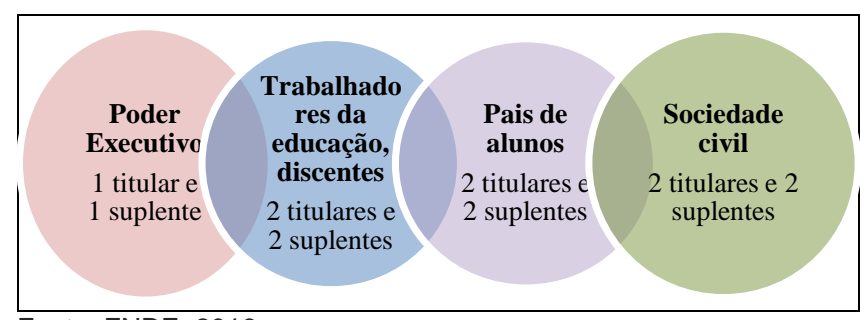

Fonte: FNDE, 2016.

Conforme consta na Figura 1, os CAEs são compostos tanto por representantes do Estado quanto da sociedade civil. Para Kronemberger (2016), os integrantes dos conselhos possuem interesses e valores diferentes, características de perfil que podem ser conflitantes. Considerando que os conselhos constituem-se em um modelo de gestão de políticas públicas participativo, a decisão é resultante de um processo de discussão entre representantes da sociedade civil e do Estado.

A escolha dos membros dos conselhos pode ocorrer de diferentes formas. No Quadro 2 apresentase as principais formas de indicação ou escolha dos conselheiros.

\section{Quadro 2: Principais formas de indicação ou escolha de conselheiros.}

\begin{tabular}{|c|c|}
\hline $\begin{array}{c}\text { Forma de indicação ou } \\
\text { escolha }\end{array}$ & Como ocorre \\
\hline $\begin{array}{l}\text { Indicados por } \\
\text { entidades/instituições/segmentos }\end{array}$ & $\begin{array}{l}\text { As entidades (integrantes } \\
\text { da sociedade civil) indicam } \\
\text { seus representantes, os } \\
\text { quais são nomeados pelo } \\
\text { prefeito. }\end{array}$ \\
\hline $\begin{array}{l}\text { Livre indicação pelo Executivo, } \\
\text { órgãos estatais ou } \\
\text { concessionários ou } \\
\text { permissionários de serviços } \\
\text { públicos }\end{array}$ & $\begin{array}{l}\text { As indicações são feitas } \\
\text { pelo prefeito ou secretarias } \\
\text { municipais, órgãos } \\
\text { estaduais e federais ou } \\
\text { empresas permissionárias } \\
\text { de serviços públicos. }\end{array}$ \\
\hline Eleição & $\begin{array}{l}\text { Por meio de processos } \\
\text { eletivos, com definição de } \\
\text { inscrição de candidatos e } \\
\text { posterior eleição. }\end{array}$ \\
\hline $\begin{array}{l}\text { Titulares do órgão máximo da } \\
\text { entidade/órgão/instituição/ poder }\end{array}$ & $\begin{array}{l}\text { Incorpora entre seus } \\
\text { integrantes a figura de } \\
\text { membros natos, em geral } \\
\text { titulares de mandatos ou } \\
\text { cargos de direção de } \\
\text { organizações sociais ou } \\
\text { entidades de classe. }\end{array}$ \\
\hline $\begin{array}{l}\text { Livre indicação pelo Poder } \\
\text { Legislativo }\end{array}$ & $\begin{array}{l}\text { Em poucas situações o } \\
\text { indicado pelo Poder } \\
\text { Legislativo é um funcionário } \\
\text { da Câmara e não um } \\
\text { vereador, como ocorrem } \\
\text { em alguns CAEs. Existem } \\
\text { conselhos mais globais } \\
\text { onde o Presidente da } \\
\text { Câmara ou um } \\
\text { representante é membro } \\
\text { nato do conselho de } \\
\text { representantes ou da } \\
\text { assembleia geral na } \\
\text { maioria dos municípios. } \\
\text { Ainda há casos de } \\
\text { vereadores ocupando } \\
\text { cargos de coordenadores } \\
\text { ou presidentes de } \\
\text { conselhos. }\end{array}$ \\
\hline
\end{tabular}

Fonte: elaboração própria a partir de Allebrandt (2016).

Conforme Allebrandt (2016), muitos conselhos vêm sendo criados com o intuito de recebimento de recursos para os municípios, sejam recursos ordinários ou mesmo vinculados a algum projeto específico. Contudo, quando o objetivo é apenas cumprir o dispositivo legal, geralmente os conselhos não têm um funcionamento regular e a indicação dos conselheiros ocorre por pessoas do Poder Executivo, servindo como objeto de homologação de decisões 
tomadas de forma unilateral (ALLEBRANDT, 2016), tornando sua atuação efetiva comprometida com ideologias político partidárias e não construída socialmente.

Diante do exposto, afirma-se que a institucionalização de um CAE nos municípios brasileiros é dependente do contexto em nível local. Mesmo que a constituição dos CAEs é exigência para - recebimento de recursos para a alimentação escolar, a atuação, funcionamento e desafios enfrentados pelos conselheiros variam de acordo com o contexto local, do espaço social e dos atores envolvidos direta e indiretamente com esse órgão.

\section{Procedimentos metodológicos}

A pesquisa que originou o presente artigo faz parte da dissertação da autora principal, na qual está sendo investigada a operacionalização do PNAE nas escolas públicas do município de Passo Fundo. Para compor este artigo, optou-se por realizar uma aproximação com o objeto de estudo no município de ljuí (RS), de forma a não antecipar a coleta de dados no município onde está sendo realizada a dissertação. Por essa razão, configura-se como uma pesquisa exploratória (GIL, 2016), desenvolvida como estudo de caso único e com abordagem qualitativa dos dados.

O caso selecionado para o estudo é o Conselho Municipal de Alimentação Escolar de ljuí, escolhido por estar vinculado ao PNAE, objeto de estudo da autora principal e com sede na cidade de ljuí, onde residem os coautores, o que facilitou a parte empírica do estudo, justificando a escolha desse conselho e da cidade onde ele está situado.

Quanto aos procedimentos de coleta dos dados, foram coletados dados primários e secundários. As fontes secundárias dos dados foi o livro sobre gestão social e conselhos gestores, cuja autoria é de Fernando Tenório e Thais Soares Kronemberger, bem como os trabalhos de Celina Souza e Leonardo Secchi sobre políticas públicas, além das Leis municipais $\mathrm{n}^{\circ}$ 3151/1995 e $\mathrm{n}$ ำ 5320/2010 e do Decreto no 2734/2000.
Os dados primários foram coletados por meio de entrevistas, as quais foram orientadas por um roteiro, sendo os sujeitos informantes selecionados entre os integrantes do CAE de ljuí: a presidente em exercício, a representante da secretaria de educação municipal e o representante de pais de alunos das escolas municipais. Além disso, utilizou-se de notícias veiculadas pela mídia local em relação a atuação do conselho em pauta neste estudo.

Segundo Basso (2012), cada aspecto da realidade que se deseja estudar envolve níveis ou etapas particulares e procedimentos específicos, nesse sentido, qualquer análise de situação de desenvolvimento (ASD) pode ser dividida em três etapas de estudo. Para o autor, o primeiro nível deve caracterizar o processo de desenvolvimento da região onde se localiza a situação ou o objeto de estudo. No segundo nível, deve ser definida a tipologia dos atores ou agentes econômicos, sociais, políticos em conformidade com o processo de identificação realizado no primeiro nível. No terceiro nível, são definidas as linhas estratégicas de desenvolvimento, tendo como objetivo melhorar as condições socioeconômicas tanto do ponto de vista dos atores caracterizados na segunda etapa quanto da sociedade local (BASSO, 2012).

Considerando os níveis descritos por Basso (2012) para ASD, neste estudo, o primeiro nível caracteriza a constituição do CAE em ljuí, de modo a buscar elementos que ajudem a compreender a atual estrutura do conselho nesse município. Na segunda etapa, foram entrevistados os sujeitos integrantes do conselho, de modo que foi possível identificar de que forma as relações entre os diferentes indivíduos influenciam nos resultados alcançados pelo CAE em ljuí. E, no terceiro nível, foram analisados os desafios enfrentados por esse conselho, o que permitiu que fossem estabelecidas estratégias para auxiliar na atuação desse CAE.

\section{Resultados e discussões}

Nesta seção são apresentadas a constituição do CAE em ljuí, as atividades que o conselho vem 
realizando ao longo de sua trajetória e os principais desafios enfrentados pelos conselheiros.

\subsection{A constituição e a função do CAE no município de ljuí}

Para que seja criado um conselho municipal, deve existir envolvimento da população do município, e isso só pode ser realizado mediante uma lei, a qual seja elaborada e aprovada na câmara de vereadores. Essa lei deve conter objetivos, composição, competências e atribuições que serão executadas por esse órgão (KRONEMBERGER; MEDEIROS; DIAS, 2016), com vistas a evitar que ocorram distanciamento dos propósitos pelos quais o conselho foi criado e passe a servir aos interesses políticopartidários do poder executivo municipal.

Em ljuí, o CAE foi criado por meio da Lei municipal no 3151/1995, em 21 de setembro de 1995, a qual foi substituída pela Lei municipal n 5320/2010. Trata-se de um órgão fiscalizador, permanente, deliberativo e de assessoramento ao Poder Executivo nas questões relativas à municipalização e à operacionalidade da merenda escolar. De acordo com o artigo 8ํㅜ da Lei $n^{\circ} 5320 / 2010$, esse conselho possui como competências:

I - acompanhar e fiscalizar o cumprimento do disposto nos artigos $2^{\circ}$ e $3^{\circ}$ da Resolução/CD/FNDE nํㅜ 38, de 16 de Julho de 2009;

II - acompanhar e fiscalizar a aplicação dos recursos destinados à alimentação escolar; III - zelar pela qualidade dos alimentos, em especial quanto às condições higiênicas, bem como à aceitabilidade dos cardápios oferecidos;

IV - receber o Relatório Anual de Gestão do PNAE e emitir parecer conclusivo acerca da aprovação ou não da execução do Programa; V - orientar sobre o armazenamento dos gêneros alimentícios nos depósitos e /ou escolas, e;

$\mathrm{VI}$ - comunicar a Entidade Executora quando da ocorrência de gêneros alimentícios vencidos e/ou estragados ou furtados, para que sejam tomadas as devidas providências.

O CAE em ljuí é formado por dois representantes da sociedade civil (sendo um membro da universidade comunitária local, a Unijuí), um do Poder Executivo (hoje, um profissional vinculado à Secretaria Municipal de Educação), dois pais de alunos das escolas municipais e dois profissionais da área da educação. Os membros do CAE são selecionados dentro de cada segmento integrante e possuem mandatos de dois anos, podendo ser prorrogados por igual período. O processo de institucionalização deste CAE seguiu a legislação do PNAE e as orientações do Poder Executivo, tendo como objetivo garantir a oferta de alimentação escolar de qualidade.

De acordo com o FNDE (2005), nos últimos anos ocorreu uma mudança de paradigma do PNAE enquanto política pública, passando de assistencialista e transferência de recursos para uma política de direito humano e controle social. Ressaltase, nesse sentido, a importância que os conselhos municipais têm para o programa de alimentação escolar.

Os conselhos se situam juntamente às secretarias de governos que são responsáveis pela definição e execução das políticas, sendo o Estado responsável por garantir as condições de infraestrutura para que os mesmos funcionem (KRONEMBERGER; MEDEIROS; DIAS, 2016). Em ljuí, o CAE utiliza as instalações físicas da Secretaria Municipal de Educação para as reuniões e tem à sua disposição o carro dessa secretaria, com o respectivo motorista, para efetuar as visitas necessárias às escolas e aos produtores rurais, quando necessário.

O funcionamento do conselho é pautado por um regimento interno, aprovado pelo Decreto $\mathrm{n}^{\circ}$ $2734 / 2000$, sendo este um documento que guia todo o seu funcionamento. O regimento interno do CAE, no entendimento de Kronemberger, Medeiros e Dias (2016, p. 167), é um:

Documento que rege o funcionamento do conselho e contém disposições sobre: finalidades, competências, atribuições, composição, organização e funcionamento etc. Deve ser elaborado pelo conselho e pode ser alterado de forma parcial ou total mediante proposta apresentada por qualquer membro do conselho e que requer, normalmente, aprovação de, no mínimo, $2 / 3$ dos seus membros. 
As responsabilidades do CAE estão relacionadas com sua finalidade e natureza (KRONEMBERGER; MEDEIROS; DIAS, 2016). De acordo com a Lei no 5.320/2010, o CAE possui caráter fiscalizador, permanente, deliberativo e de assessoramento nas questões relativas à municipalização e à operacionalidade da merenda escolar. A principal distinção quanto ao teor das competências exercidas pelos conselhos reside em seu caráter consultivo ou deliberativo (KRONEMBERGER; MEDEIROS; DIAS, 2016), tendo o CAE caráter deliberativo.

Conforme disposto na Lei $\mathrm{n}^{\circ} \mathbf{5} .320 / 2010$, caso haja irregularidade na execução do PNAE, o CAE deve formalizar a denúncia ao FNDE, à Secretaria Federal de Controle do Ministério da Fazenda, ao Ministério Público Federal e ao Tribunal de Contas da União nos Estados.

\subsection{A atuação do CAE em ljuí}

As reuniões ordinárias do CAE em ljuí ocorrem mensalmente e nelas são discutidos assuntos definidos previamente e também questões trazidas pelos membros, sendo essas reuniões abertas e públicas, realizadas na sala de reuniões da Secretaria Municipal de Educação. As reuniões extraordinárias ocorrem conforme a necessidade. Segundo Kronemberger, Medeiros e Dias (2016), a participação nos conselhos deve ser aberta e todo cidadão pode se fazer presente e participar das reuniões, realizando o acompanhamento e a fiscalização das ações do poder público. Nas reuniões do CAE de ljuí, todos têm direito à fala e as decisões são tomadas em consenso, com a maioria presente, dependendo do quórum mínimo para que possam ser incorporadas ao regimento interno.

A gestão social é um campo de estudos que tem como propósito refletir teoricamente as possibilidades da gestão pública mais democrática. Para Tenório (2016a, p. 13), isso é possível por meio de um "processo gerencial participativo onde a autoridade decisória é compartilhada entre os envolvidos na ação", por meio da formação de conselhos gestores, cujas reuniões seguem a ordem indicada na Figura 2.

Figura 2: Funcionamento das reuniões dos conselhos.

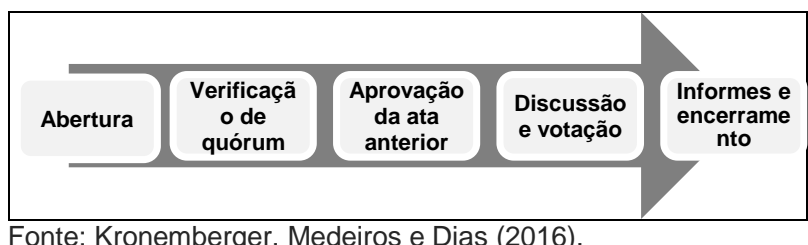

O processo de instalação das referidas reuniões do CAE em ljuí se inicia com a sua presidente realizando a abertura da reunião e a chamada dos conselheiros com vistas à verificação do quórum. Uma vez instalada a reunião, a primeira atividade consiste na leitura da ata da reunião anterior e submissão à apreciação dos presentes com vistas à sua aprovação. A atividade seguinte é apreciar os pontos elencados na pauta, os quais são específicos a cada reunião. Por fim, são dados os informes e avisos aos conselheiros e é anunciado pelo presidente o término da reunião.

Quanto à composição de seus integrantes, o CAE de ljuí encontra-se em fase de recomposição, pois havia dificuldades constantes de quórum deliberativo. Conforme relato da presidente, as reuniões não estavam ocorrendo com a frequência necessária para a atuação efetiva e, quando ocorriam, não havia integrantes suficientes para tomar as decisões. Dessa forma, a presidente solicitou a recomposição dos membros do conselho. A proposta da presidente é que os atuais membros do CAE consigam cumprir a agenda de reuniões e visitas nas escolas e nos agricultores, para que, desse modo, o conselho cumpra seu papel com a sociedade, realizando efetivamente o controle social do PNAE.

As reuniões são marcadas com assuntos previamente definidos, no entanto, o conselho não estava evoluindo da segunda etapa, conforme se visualiza na Figura 2, pois nem todos os membros estavam se fazendo presentes nas datas definidas. Identifica-se um empenho por parte da atual 
presidente para que o conselho consiga continuar atuante no município.

Quando questionados sobre as atividades desenvolvidas, os entrevistados relatam que o CAE desempenha seu papel conforme prevê a legislação e também elabora anualmente o seu "plano de ações" de acordo com a demanda que se apresenta no município, executando-o sistematicamente durante o decorrer do ano vigente. O CAE acompanha os relatórios das compras efetuadas pelo município com o dinheiro que o FNDE repassa, o qual deve ser destinado a gêneros alimentícios para a merenda escolar, de forma que, no mínimo, 30\% sejam destinados a produtos de agricultores familiares locais.

O conselho também oferece cursos de formação para manipuladores de alimentos nas escolas, no entanto, a presidente relata que ter um responsável técnico em cada escola facilitaria o controle para não haver desperdícios, no entanto, a disponibilização desse profissional tem se mostrado um dos desafios no município.

Em relação à importância do $\mathrm{CAE}$ para 0 sucesso do PNAE, os três entrevistados relataram que esse órgão é muito importante. Na fala da presidente:

não é só mais um conselho, é um conselho que tem o papel de controle social, de fiscalização de gestão de recursos e também do próprio fazer, do executar da alimentação escolar, nas próprias cozinhas com as merendeiras".

Em relação a atuação dos conselheiros do CAE e a comunicação e articulação com outros setores e órgãos ligados à gestão do PNAE em ljuí, como a Coordenadoria de Nutrição Escolar e a Secretaria de Educação, pode-se dizer que existe interação e dialogicidade entre os atores dos diferentes órgãos. Estas relações visam fortalecer a atuação deste conselho e a compreensão do mesmo enquanto espaço público e de exercício da cidadania deliberativa ${ }^{1}$.

\footnotetext{
${ }^{1}$ A cidadania deliberativa significa que a legitimidade, a validade das decisões, deve originar de processos de
}

\subsection{Desafios enfrentados pelo CAE em ljuí}

Com a implementação da Lei no 11.947/2009, ficou determinado que, dos recursos repassados pelo FNDE ao município, no mínimo 30\% devem ser investidos na aquisição de produtos de origem da agricultura familiar (FNDE, 2016). Em relação à referida Lei, a presidente do CAE relatou que:

significa um desafio "sem tamanho", é preciso que $0 \mathrm{CAE}$ avance muito, 0 próprio desconhecimento do conteúdo e teor da lei é um fator muito limitante, em que os integrantes do conselho e os próprios envolvidos não conhecem. Os conselheiros precisam ler a cartilha da alimentação escolar, o manual do FNDE sobre o PNAE, os documentos disponibilizados no site do CECANE, estas são leituras obrigatórias.

O CAE vem se mobilizando, com o apoio do secretário de Educação, para que as dirigentes das escolas incentivem os alunos a se alimentar da refeição oferecida na própria instituição, e, no caso das que possuem cantinas e bares, para que estas não ofereçam aos alunos alimentos processados e ultraprocessados, uma vez que estes são prejudiciais à saúde.

O secretário de Educação é participativo e atua em favor de melhorias para a execução do PNAE no município, auxiliando o desempenho das atividades do conselho, mas não se sobrepõe a esse órgão. A relação entre o conselho e o poder executivo local é de reciprocidade e existe interação e dialogicidade entre os atores dos diferentes órgãos: integrantes do conselho, secretário de Educação municipal, coordenação do programa e dirigentes das escolas, sendo realizadas reuniões para discutir os problemas existentes, procurando alternativas para as ações que precisam ser executadas para auxiliar na atuação do CAE.

Esse modelo de atuação do conselho vai ao encontro do que Paes de Paula $(2003,2005)$ apud Klering, Porsse e Guadagnin (2010) denomina de "vertente alternativa" ou "vertente societal".

discussão, orientados pelos princípios da inclusão, do pluralismo, da igualdade de participação e do bem comum (TENÓRIO, 2016b). 
Nesta perspectiva da administração pública, apoiando-se em diferentes autores, Klering, Porsse e Guadagnin (2010, p. 9) afirma:

há um maior envolvimento da população na definição da agenda política, e, consequentemente, um maior controle social sobre as ações estatais e a legitimação da sociedade como participante do processo de formulação e implementação de políticas públicas.

Nesse tipo de gestão, o indivíduo participa decidindo seu destino, tanto como cidadão, eleitor e trabalhador quanto como consumidor e a lógica que determina essa atuação é a da democracia (KLERING; PORSSE; GUADAGNIN, 2010). No CAE, as decisões são tomadas em conjunto por meio de votação e todos os integrantes têm direito à fala, existe a participação do cidadão.

Para Tenório (2016a), a participação deve ter como característica a utilização de um método que facilite o envolvimento dos cidadãos, no entanto, devem-se perceber as diferenças entre participação manipulada, participação por cooptação ou a pseudoparticipação. Para o autor, na participação manipulada, os indivíduos são controlados por outros; na participação por cooptação, os indivíduos são aliciados; e na pseudoparticipação, os indivíduos se fazem presentes, mas são impedidos por algum motivo de colaborar.

Para que a participação efetivamente ocorra, Tenório e Rozenberger (1997) apud Tenório (2016a) evidenciam que ela depende de três atributos:

a) $\quad \mathrm{O}$ indivíduo participante deve estar consciente de seus atos e compreender as atividades que está vivenciando;

b) Não pode ser uma participação forçada;

c) Não pode ocorrer coação ou imposição, deve ser uma participação voluntária.

Com base em seu discurso, é possível perceber que os entrevistados estão vinculados ao conselho de forma voluntária e sentem-se comprometidos. De acordo com a presidente:
$\mathrm{Eu}$ sou quase patrimônio do CAE. Desde 2003, quando entrei na Unijuí, eu já me vinculei ao CAE. A Secretaria de Educação sempre enviou pra Unijuí um convite para compor o CAE como membro da sociedade civil. Como sempre trabalhei nessa área de alimentação escolar, fui uma das indicadas para compor. Eu lembro que num primeiro período eu fiquei toda a gestão, entrei na metade, já estava em andamento, finalizei o mandato, fiquei mais uma gestão e precisei me afastar e fiquei um tempo fora, agora eu entrei de novo. Eu estou no CAE porque gosto, porque amo.

Atualmente, os integrantes do CAE, em conjunto com o secretário de Educação, vêm argumentando para as funcionárias das escolas que não devem vender alimentos processados $\mathrm{e}$ ultraprocessados em suas cantinas. Em algumas escolas que possuem cantinas, é permitido que os alunos comprem a merenda, outros trazem lanches de casa, e, em outros dias, utilizam o lanche do refeitório. Tudo isso se insere em um contexto, no entanto, que os recursos que vêm do FNDE não são utilizados em sua totalidade. Segundo o relato dos entrevistados, tal situação não se efetiva na totalidade das escolas, mas é uma realidade dentro do programa e se constitui em um desafio que o $\mathrm{CAE}$ está enfrentando. Sobre isso, a presidente do Conselho destaca:

No meu ponto de vista, não poderia ser permitido que as crianças trouxessem dinheiro de casa para comprar no bar. Trazer lanche de casa até pode ser autorizado, mas deveria ser incentivado que a criança coma a merenda oferecida pela escola. Nesse sentido, também entra o papel da educação alimentar.

O estrato da fala da referida presidente reitera a importância do papel da escola como parceira da família, incentivando que o que a criança aprende tanto em casa quanto na escola em termos de bons hábitos alimentares deve ser consolidado. Reitera também que, para o conselho exercer seu papel, é necessário que seus membros tenham amplo conhecimento da legislação que rege o PNAE. Tal pensamento é sustentado por Allebrandt (2016), que considera fundamental os conselheiros terem compreensão de seus atos e ações, ou seja, razões e 
consequências de suas decisões. Esse entendimento reforça a importância de os conselheiros conhecerem os documentos que norteiam o PNAE.

Os dados indicam que o CAE em ljuí é atuante e desenvolve suas atividades em consonância com a legislação em vigor. Suas reuniões ordinárias devem ocorrer mensalmente e, nesse espaço, devem ser discutidos assuntos relevantes aos interesses do CAE. Nessas reuniões, os conselheiros sentem-se livres para se expressar sobre assuntos que não estão na pauta da reunião e a dinâmica interna revela espaço social para interação e dialogicidade entre seus membros e empenho destes para realizar um trabalho efetivo em benefício da comunidade.

O processo de reestruturação do quadro de conselheiros se fez necessário e se revelou como importante na busca pelo cumprimento da agenda de reuniões e a necessidade de quórum para a efetiva tomada de decisões. Os conselheiros atuais demonstram empenho e comprometimento no papel que representam junto aos interesses da sociedade local, apesar dos desafios enfrentados.

\section{Considerações finais}

Com 0 intuito de compreender a institucionalização e o funcionamento do CAE enquanto um conselho gestor de política pública, sua atuação e os desafios encontrados, este estudo analisou a realidade de um CAE à luz das teorias e conceitos de políticas públicas, gestão social e conselhos gestores. Os resultados indicam que, para constituir um conselho municipal, deve haver envolvimento da população e uma lei aprovada na Câmara de Vereadores do município do qual faz parte. Internamente, seu funcionamento deve ser regido por um regimento interno e sua finalidade e natureza são fiscalizador, permanente, deliberativo e de assessoramento nas questões relativas a municipalização da merenda escolar.

Tendo em vista as características e funções de um CAE, os resultados evidenciam a importância da atuação deste órgão para a efetividade do PNAE no âmbito local. A rotatividade dos integrantes do conselho observadas no caso estudado é um desafio enfrentado por este CAE, pois dificulta a tomada de decisões nas reuniões que precisam de um quórum deliberativo. Para que o CAE consiga desempenhar suas funções com êxito é necessário que exista uma relação de dialogicidade entre este órgão e o Poder Executivo local e com os diferentes atores dos diferentes órgãos envolvidos com o PNAE.

Conclui-se que em ljuí a relação entre o CAE e o Poder Executivo local é de reciprocidade. Existe interação e dialogicidade entre os atores dos diferentes órgãos: integrantes do CAE, secretário de educação municipal, coordenação do programa de alimentação escolar e dirigentes das escolas, sendo realizadas reuniões para discutir os problemas existentes, procurando alternativas e ações que possam auxiliar na atuação do CAE. A atuação de um CAE contribui para que o PNAE produza efetividade da política pública, bem como contribua para o desenvolvimento dos alunos participantes do sistema educacional público brasileiro e confere garantias aos agricultores familiares locais terem acesso ao mercado institucional que o programa proporciona.

Limitação do estudo. A estratégia estudo de caso único configura-se como um limitador para generalizar os resultados, contudo representa uma aproximação que evidencia questões de contexto na constituição e funcionamento de um CAE nos municípios brasileiros.

\section{Referências}

ALLEBRANDT, S. L. Conselhos Municipais: potencialidades e limites para a efetividade e eficácia de um espaço público para a construção da cidadania interativa. In: ENANPAD, 27, 2003, Atibaia. Anais... Atibaia: Anpad, 2003.

ALLEBRANDT, S. L. Os conselheiros municipais. In: TENÓRIO, F. G.; KRONEMBERGER, T. S. (orgs.). Gestão social e conselhos gestores. Rio de Janeiro: FGV, 2016. p. 207-230.

BASSO, D. Fundamentos teóricos e procedimentos metodológicos para a análise de processos reais de desenvolvimento. In: SIEDENBERG, D. R. (Org.). Desenvolvimento sob múltiplos olhares. ljuí: Unijuí, 2012. p. 101-137. 
FROEHLICH, E. A capacidade de "Fazer Diferente": os condicionantes legais e as estratégias de governança na implementação do programa de alimentação escolar em Dois Irmãos e Tapes (RS). 2010. 152f. Dissertação (Mestrado em Desenvolvimento Rural)- Universidade Federal do Rio Grande do Sul, Porto Alegre.

FNDE. Fundo Nacional de Desenvolvimento da Educação. PNAE. Programa Nacional de Alimentação Escolar: histórico e perspectivas. In: ENCONTRO NACIONAL DE EXPERIÊNCIAS INOVADORAS EM ALIMENTAÇÃO ESCOLAR, 2, 2005, Brasília. Disponível em: <http://www.fnde.gov.br/programas/proinfancia/ proinfancia-perguntas-frequentes/item/3004$2 \% \mathrm{C} 2 \% \mathrm{B0}$-encontro-nacional-deexperi\%C3\%AAncias-inovadoras-emalimenta\%C3\%A7\%C3\%A3o-escolarnovembro-2005>. Acesso em: 6 fev. 2017.

Sobre o PNAE. Disponível em: <http://www.fnde.gov.br/index.php/programas/a limentacao-escolar/alimentacao-escolarapresentacao>. Acesso em: 17 nov. 2016.

GIL, A. C. Métodos e técnicas de pesquisa social. São Paulo: Atlas, 2016.

IJUÍ (Município). Lei no 3151, de 21 de setembro de 1995. Cria o Conselho de Alimentação Escolar - CAE e dá outras providências. Disponível em:

<https://leismunicipais.com.br/a1/rs/i/ijui/leiordinaria/1995/315/3151/lei-ordinaria-n-31511995-cria-o-conselho-municipal-dealimentacao-escolar-conales-e-da-outrasprovidencias>. Acesso em: 5 fev. 2017.

IJUÍ (Município). Decreto no 2734, de 10 de novembro de 2000. Aprova o regimento interno do Conselho de Alimentação Escolar - CAE. Disponível em: <https://leismunicipais.com.br/a1/rs/i/ijui/decret o/2000/274/2734/decreto-n-2734-2000-aprovao-regimento-interno-do-conselho-dealimentacao-escolar-cae>. Acesso em: 06 fev. 2017.

IJUÍ (Município). Lei nำ 5320, de 10 de setembro de 2010. Dispõe sobre a organização, funcionamento e atuação do Conselho de Alimentação Escolar - CAE revoga leis que menciona e dá outras providências. Disponível em: <https://leismunicipais.com.br/a/rs/i/ijui/leiordinaria/2010/532/5320/lei-ordinaria-n-53202010-dispoe-sobre-a-organizacaofuncionamento-e-atuacao-do-conselho-dealimentacao-escolar-cae-revoga-leis-quemenciona-e-da-outras-providencias $>$. Acesso em: 06 fev. 2017.

LAVINAS, L. V.; MAGNO, V. Histórico dos conselhos de políticas públicas. In: TENÓRIO, F. G.; KRONEMBERGER, T. S. (Orgs.). Gestão social e conselhos gestores. Rio de Janeiro: FGV, 2016. p. 119 - 149.

MOSIMANN, E. N. Agricultura familiar e alimentação escolar nas encostas da serra geral de Santa Catarina: desafios e potencialidades. 2014. 212f. Dissertação (Mestrado em Agroecossistemas)- Universidade Federal de Santa Catarina, Florianópolis.

KLERING, L. R.; PORSSE, M. C. S.; GUADAGNIN, L. A. Novos caminhos da administração pública brasileira. Análise, v. 21, n. 1, p. 4-17, 2010.

KRONEMBERGER, T. S. Os conselhos municipais na prática: quais limitações? In: TENÓRIO, F. G.; KRONEMBERGER, T. S. (Orgs.). Gestão social e conselhos gestores. Rio de Janeiro: FGV, 2016. p. 231 - 255.

KRONEMBERGER, T. S.; MEDEIROS, A. C.; DIAS, A. F. Conselhos Municipais: institucionalização e funcionamento. In: TENÓRIO, F. G.; KRONEMBERGER, T. S. (Orgs.). Gestão social e conselhos gestores. Rio de Janeiro: FGV, 2016. p. 151-182.

TENÓRIO, F. G. Gestão social, território e participação. In: TENÓRIO, F. G. (Org.). Cidadania, território e atores sociais. Rio de Janeiro: FGV, 2016a. p. 61-85.

TENÓRIO, F. G. Gestão social: conceito. In: TENÓRIO, F. G.; KRONEMBERGER, T. S. (Orgs.). Gestão social e conselhos gestores. Rio de Janeiro: FGV, 2016b. p. 13-34.

TRICHES, R. M. Reconectando a produção ao consumo: a aquisição de gêneros alimentícios da agricultura familiar para o Programa de Alimentação Escolar. 2010. 297f. Tese (Doutorado em Desenvolvimento Rural)Universidade Federal do Rio Grande do Sul, Porto Alegre.

VILLELA, L. E.; MEDEIROS, A. C. Dinâmica política dos atores sociais. In: TENÓRIO, F. G.; KRONEMBERGER, T. S. (orgs.). Gestão social e conselhos gestores. Rio de Janeiro: FGV, 2016, p. 207-230. 